Vol. 2, No. 2, Desember 2017, pISSN 2527-2853, eISSN 2549-2985

\title{
Desain Plafon pada Auditorium Gedung Kesenian Jakarta
}

\author{
Karina Juwita \\ Fakultas Desain Interior Universitas Tarumanagara \\ karinarustandy@yahoo.com
}

\begin{abstract}
ABSTRAK
Auditorium merupakan tempat untuk kegiatan publik seperti pertunjukan kesenian, olahraga, dan kegiatan seremonial. Pertunjukan kesenian seperti teater, opera, dan musik bisa dinikmati dengan nyaman tergantung dari kualitas akustik ruang. Salah satu faktor yang mempengaruhi auditorium adalah plafon. Plafon bukan hanya sebagai estetika ruangan tetapi bentuk plafon juga harus menyesuaikan ruangan agar tidak terjadi gema dan suara dapat didengar secara jelas oleh penonton. Pada penelitian ini dilakukan di Auditorium Gedung Kesenian Jakarta untuk mengetahui apakah terdapat cacat akustik pada auditorium tersebut dan solusi apabila terjadi cacat akustik.
\end{abstract}

Kata Kunci: akustik; auditorium

\begin{abstract}
Auditorium is a place for public activities such as art performances, sports, and ceremonial activities. Art performances such as theater, opera, and music can be enjoyed comfortably depending on the acoustic quality of space. One of the factors affecting the auditorium is the ceiling. Ceiling is not only as aesthetics of the room but the shape of the ceiling should also adjust the room to avoid echoes and the sound can be heard clearly by the audience. This research was conducted at the Gedung Kesenian Jakarta Auditorium to find out if there are acoustic defects in the auditorium and the solution in case of acoustic defects.
\end{abstract}

Keywords: acoustic; auditorium

\section{PENDAHULUAN}

Plafon atau langit-langit merupakan bidang atas bagian dalam dari ruangan bangunan. Plafon merupakan salah satu unsur utama pembentuk ruang. Selain itu plafon juga dapat sebagai acuan nilai akustik yang ada pada suatu bangunan. Desain dan pemasangan plafon didesain sedemikian rupa untuk mendapatkan nilai akustik dan kesan keindahan interior ruangan tanpa mengurangi kenyamanan manusia yang ada di ruangan tersebut.

Namun setiap ruang memiliki bentuk plafon yang berbeda tergantung dari fungsi ruang tersebut. Salah satu ruang yang merupakan jenis auditorium adalah teater. Sebuah auditorium seringkali harus menyediakan tempat untuk pengunjung dan kapasitas ruang harus secara mudah disesuaikan dengan kebutuhan sesaat. Ketika penonton ingin memasuki suatu auditorium, ia mempunyai hak untuk mengharapkan seperti kualitas acaranya sendiri, kenyamanan, keamanan, lingkungan yang menyenangkan, penerangan yang cukup dan bunyi yang baik. Untuk menjaga aktivitas di ruangan ini agar tidak mengganggu ruangan lain adalah dengan menerapkan teknik akustik.

Bentuk plafon yang desain pemasangannya bertingkat-tingkat digunakan sebagai perbaikan kualitas akustik pada suatu ruangan. Prinsip utama dalam desain akustik adalah memperkuat dan mengarahkan bunyi yang berguna serta menghilangkan atau memperlemah bunyi yang tidak berguna untuk pendengaran manusia kurang menyenangkan.

Bentuk dan pola plafon menurut (Bradley, 1989) sangat mempengaruhi tingkat kekerasan bunyi (loudness) pada auditorium, karena memperkaya pantulan awal yang berguna. Hal ini disebabkan karena plafon merupakan permukaan reflector yang paling luas bidang cakupannya 
bila dibandingkan dengan pantulan yang berasal dari dinding samping yang melingkupi area terbatas di sekitarnya (Talaske \& Boner, 1986). Oleh karena itu, pola plafon perlu didesain untuk mengarahkan pantulan-pantulan bunyi dengan tepat. Fitting dari sistem pencahayaan dan fasilitas ventilasi yang dipasang di dalam panel plafon tersebut dapat berpindah bersamaan dengan setting panelnya pada pengaturan volume kecil atau besar. Untuk pertunjukkan konser biasanya plafon diatur pada posisi atas. Selain itu, waktu dengung juga dapat diperpanjang secara elektro akustik dengan memakai assisted resonance system pada semua frekuensi sehingga dapat meningkatkan waktu dengung sampai dengan $80 \%$ pada frekuensi rendah dan 25\% pada frekuensi tinggi (Talaske \& Boner, 1986). Berdasarkan itu semua, penulis ingin membahas plafon yang ada pada ruang auditorium dan melakukan penelitian dengan judul “Plafon pada Auditorium Gedung Kesenian Jakarta”.

\section{A. Pengertian dan Fungsi Plafon}

Plafon adalah bagian dari konstruksi bangunan yang berfungsi sebagai langit-langit bangunan. Pada dasarnya plafon dibuat dengan maksud untuk mencegah cuaca panas atau dingin agar tidak langsung masuk ke dalam rumah setelah melewati atap. Namun plafon tidak lagi hanya sekedar penghambat panas atau dingin, melainkan juga sebagai hiasan yang akan lebih mempercantik interior suatu bangunan. Plafon biasanya dibuat dengan ketinggian tertentu. Namun sebagai variasi ada juga yang dibuat tidak selalu rata. Variasi tersebut dikenal sebagai plafond drop ceiling. Plafon dibuat lebih tinggi dari yang lain. (Imelda Akmal, 2007:4).

Fungsi plafon adalah sebagai batas tinggi suatu ruangan sehingga ruangan tidak kelihatan melompong, penahan fungsi plafon adalah adalah sebagai batas tinggi suatu ruangan sehingga ruangan tidak kelihatan melompong, penahan berbagai kotoran berukuran kecil yang jatuh dari celah-celah genteng, penahan percikan air hujan yang jatuh melalui celah genteng, isolator atau pengatur rasa panas dan dingin yang berasal dari atap, penutup rangka atap agar ruangan terlihat rapi dan bersih, peredam suara, baik yang ditimbulkan oleh air hujan maupun suara lainnya, tempat menggantungkan komponen penerangan (Gatut Susanta, 2008:124-125).

\section{B. Pengertian Akustik}

Akustik (dari bahasa Yunani akouein = mendengar) adalah ilmu terapan yang dimaksudkan untuk memanjakan indra pendengaran Anda di suatu ruang tertutup terutama yang relatif besar. Akustik lingkungan atau pengendalian bunyi secara arsitektural merupakan suatu cabang pengendalian lingkungan pada ruang arsitektural. Ia dapat menciptakan suatu lingkungan di mana kondisi mendengarkan secara ideal disediakan baik ruang tertutup maupun di udara terbuka dan penghuni ruang arsitektural di dalam maupun di luar akan cukup dilindungi terhadap bising dan getaran yang berlebihan. maupun di udara. (Lea\&Leslie, 1972:51)

Pada pembahasan ini, lebih mengarah kepada material plafon yang berfungsi sebagai akustik ruang yang digunakan di dalam Auditorium Gedung Kesenian Jakarta. Material plafon akustik merupakan material plafon yang tahan terhadap batas ambang kebisingan tertentu, dan dapat meredam suara sehingga untuk kebutuhan ruangan tertentu banyak dipakai oleh masyarakat.

\section{Pengertian Auditorium}

Auditorium merupakan sebuah bangunan atau ruangan besar yg digunakan untuk mengadakan pertemuan umum, pertunjukan, dsb. dalam Gedung Kesenian Jakarta. Auditorium digunakan untuk pertunjukan seni musik, seni teater, dan seni tari (M. Rettiger, 1970:109). 


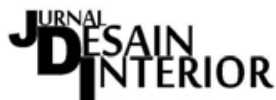

Vol. 2, No. 2, Desember 2017, pISSN 2527-2853, eISSN 2549-2985

\section{Dampak dari Cacat Akustik}

Di samping menyediakan sifat-sifat akustik yang positif, seperti kekerasan yang cukup, distribusi energi bunyi yang merata, dan waktu dengung optimum, cacat akustik perlu ditiadakan. Cacat akustik yang paling sering dijumpai adalah gema (pemantulan yang berkempanjangan), pemusatan bunyi (pada permukaan cekung), ruang gandeng,distorsi (perubahan kualitas bunyi yang tidak dikehendaki), resonansi ruang, bayangan bunyi, serambi bisikan, pemantulan yang berkepanjangan (sejenis gema tetapi penundaan waktu antara penerimaan bunyi langsung dan bunyi pantul lebuh singkat), dan gaung (gema-gema kecil yang berturutan dengan cepat dan dapat dicatat serta diamati bila ledakan bunyi singkat) (Lea\&Leslie, 1972:65).

\section{E. Cara Menghindari Cacat Akustik}

Bentuk dan pola plafon sangat mempengaruhi tingkat kekerasan bunyi (loudness) pada auditorium, karena memperkaya pantulan awal yang berguna. Hal ini disebabkan karena plafon merupakan permukaan reflektor yang paling luas bidang cakupannya bila dibandingkan dengan pantulan yang berasal dari dinding samping yang melingkupi area terbatas di sekitarnya. Oleh karena itu, pola plafon perlu didesain untuk mengarahkan pantulan-pantulan bunyi dengan tepat. Fitting dari sistem pencahayaan dan fasilitas ventilasi yang dipasang di dalam panel plafon tersebut dapat berpindah bersamaan dengan setting panelnya pada pengaturan volume kecil atau besar (Bradley, 1989:226).

Untuk pertunjukkan konser biasanya plafon diatur pada posisi atas. Selain itu, waktu dengung juga dapat diperpanjang secara elektro akustik dengan memakai assisted resonance system pada semua frekuensi sehingga dapat meningkatkan waktu dengung sampai dengan 80\% pada frekuensi rendah dan 25 \% pada frekuensi tinggi. (Talaske \& Boner, 1986:176).

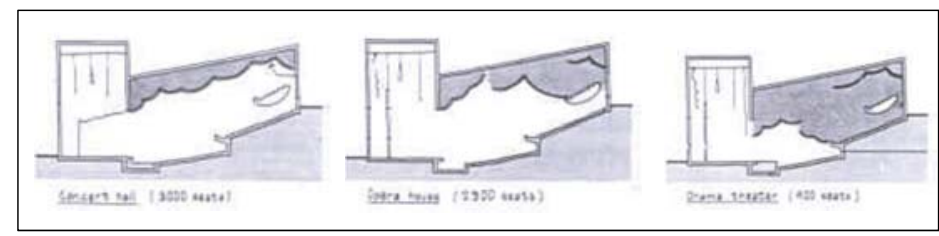

Gambar 1. Pemakaian plafon yang dapat diatur (mobile), dapat mengurangi volume auditorium secara signifikan

Sumber: Heinrich Kuttruff (1979)

Dalam sebuah ruangan teater, selain plafon akustik juga perlu diperhatikan bahan peredam suara pada dinding, material- material apa saja yang digunakan, bahan yang dipakai untuk bangku penonton, dan berbagai hal lainnya guna menunjang sistem akustik pada ruangan teater secara maksimal.

Plafon bentuk cekung bersifat pemusatan suara yang tidak menyebar dan bentuk tersebut merupakan kebalikan dari fungsi reflektor. Bentuk cekung menimbulkan efek focalpoint atau sebagai pusat arah pantulan suara, disebut whispering gallery atau gema yang merambat. Bentuk cekung bila diolah menurut rambatan suara akan lebih mendukung kondisi akustik. Bentuk cekung yang memiliki permukaan datar atau rata dapat berfungsi sebagai akustik bila diletakkan dengan kemiringan agar memiliki arah pantulan. Bentuk akustik datar dapat diolah untuk mengarahkan suara ke daerah penerima yang luasnya ditentukan oleh besar kemiringan atau sudut datang gelombang agar mampu meningkatkan jumlah pantulan dan mengurangi cacat bunyi berupa gema melalui TDG (Perbedaan jarak dengung) (Pamudji Suptandar, 2004:98). 
Bentuk cembung merupakan bentuk pemantul suara yang baik karena memiliki sifat penyebar gelombang suara yang ikut mendukung kondisi difusi akustik ruang. Bentuk cembung bisa menciptakan kejelasan suara dari berbagai arah yang cukup luas dan menyebar. Bentuk akustik datar sifatnya paling sederhana dan jelas.Bentuk akustik datar dengan teknik geometri akan memberikan suara yang jelas kepada para penonton yang duduk di deret paling belakang tanpa cacat dan perbedaan tempo penerimaan (Pamudji Suptandar, 2004:99).

Karakteristik akustik dasar adalah semua bahan berpori, seperti papan serat, plesteran lembut, mineral woods, dan selimut isolasi adalah suatu jatringan selular dengan pori-pori yang saling berhubungan. Energi bunyi dating diubah menjadi energy panas dalam pori-pori ini. Bagian bunyi yang datang diserap sedangkan sisanya yang terlah berkurang energinya, dipantulkan oleh permukaan (Lea\&Leslie, 1972:34).

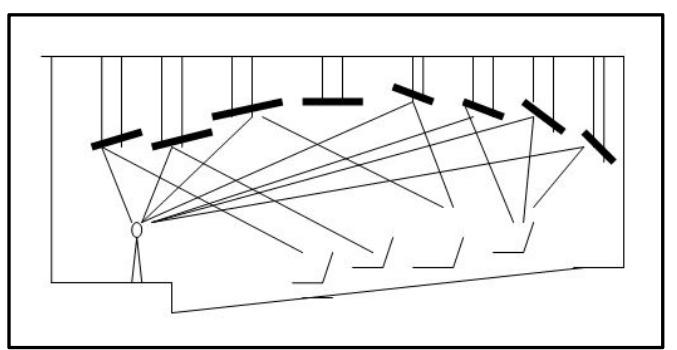

Gambar 2. Penempatan langit-langit pemantul Sumber: Leslie Doelle (1990)

Permukaan-permukaan pemantul bunyi (acoustical board, plywood, gypsum board dan lain-lain) yang memadai akan memberikan energi pantul tambahan pada tiap-tiap bagian daerah penonton, terutama pada bagian yang jauh. Ukuran permukaan pemantul harus cukup besar dibandingkan dengan dengan panjang gelombang bunyi yang akan dipantulkan. Sudut-sudut permukaan pemantul harus ditetapkan dengan hukum pemantulan bunyi dan langit-langit serta permukaan dinding perlu dimanfaatkan dengan baik agar diperoleh pemantulan-pemantulan bunyi singkat yang tertunda dalam jumlah yang terbanyak. Disarankan bentuk permukaan pemantul bunyi yang miring dengan permukaan yang tidak beraturan, terutama daerah plafond di atas sumber bunyi, agar sebagian besar bunyi langsung (direct sound) menyebar ke arah penonton dengan waktu tunda yang panjang sehingga bunyi langsung dapat diterima sebagian besar penonton hingga ke tempat duduk terjauh (Lea\&Leslie, 1972:65).

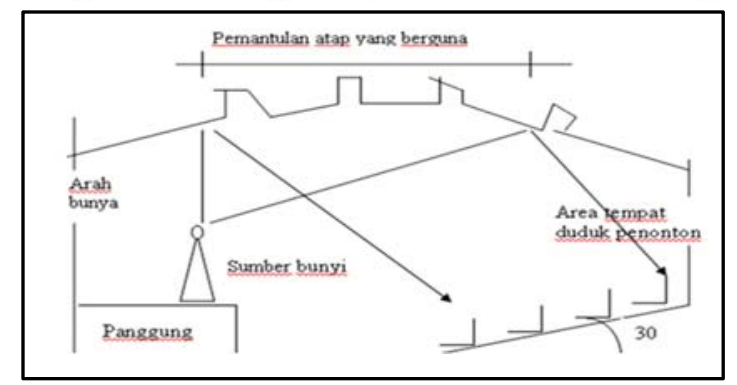

Gambar 3. Pemantulan yang dianjurkan Sumber: Leslie Doelle (1990)

Disarankan bentuk permukaan pemantul bunyi yang miring dengan permukaan yang tidak beraturan, terutama daerah plafond di atas sumber bunyi, agar sebagian besar bunyi langsung (direct sound) menyebar ke arah penonton dengan waktu tunda yang panjang sehingga bunyi 
langsung dapat diterima sebagian besar penonton hingga ke tempat duduk terjauh. (Lea\&Leslie,1972:66).

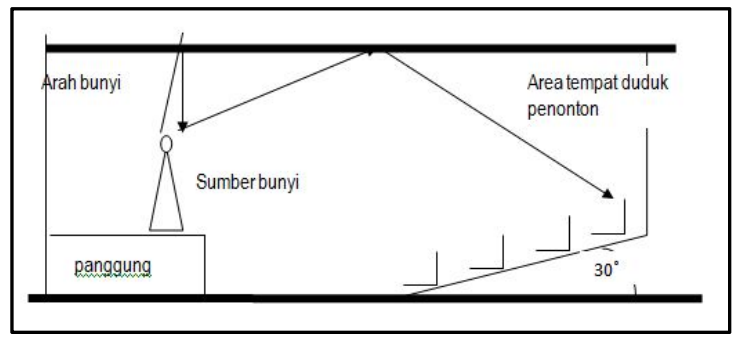

Gambar 4. Bentuk plafon paralel tidak dianjurkan Sumber: Leslie Doelle (1990)

Pada gambar di atas terjadi pemantulan kembali sebagian besar bunyi langsung (direct sound) ke sumber bunyi, dan sebagian lagi dipantulkan ke langit-langit dengan waktu tunda singkat yang terbatas baru kemudian disebarkan ke arah penonton sehingga bunyi langsung yang diterima penonton lebih sedikit sehingga kekerasan sangat berkurang (Lea\&Leslie,1972:66).

\section{METODE PENELITIAN}

Metode yang digunakan dalam penelitian ini adalah metode deskriptif dimana objek penelitian yaitu plafon pada ruang auditorium Gedung Kesenian Jakarta. Penelitian dilaksanakan pada hari Kamis, 10 November 2016 pukul 12.00 - 15.00 WIB. Teknik pengumpulan data dengan mengobservasi auditorium Gedung Kesenian Jakarta dan mencari literatur tentang plafon akustik menggunakan metode kualitatif.

\section{HASIL DAN PEMBAHASAN}

Berdasarkan hasil wawancara dengan narasumber atau informan bernama Putu Dewiyanti Delim selaku Kabsudiv. Humas, maka peneliti dapat menganalis tentang plafon yang digunakan pada Auditorium Gedung Kesenian Jakarta. Adapun hasil wawancara penulis dengan Kabsudiv.Humas mengatakan bahwa:

“Tahun 1814 waktu Inggris sebagai penjajah pulau Jawa. Gubernur Sir Stamford Raffles menyadari harus mempunyai tempat hiburan, dan akhirnya membangun sebuah gedung yang berkapasitas 250 orang. Setelah revolusi tahun 1945, gedung tersebut tetap dipakai sebagai teater tempat pementasan kesenian, namun kondisi dari teater tersebut tidak terpelihara dan terawat, lalu tahun 1968 Pusat Kesenian Jakarta Taman Ismail Marzuki diresmikan, seluruh kegiatan kesenian pindah ke Taman Izmail Marzuki. Pada tanggal 5 September 1987 Gedung Kesenian Jakarta diresmikan oleh Gubernur R. Suprapto yang menjabat sebagai Gubernur KDKI Jakarta pada periode itu dan Gedung Kesenian Jakarta kembali sebagai teater yang mempergelarkan kesenian, serupa masa lampau.”

Berdasarkan hasil wawancara mengenai plafon Putu Dewiyanti Delim mengatakan bahwa "Plafon yang digunakan adalah plafon gypsum untuk memantulkan suara dan juga bentuk lengkung pada plafon supaya pemantulan suara merata ke tempat duduk penonton. Pada bagian belakang ada plafon berongga mempunyai material kayu. Di belakang material kayu ada busa tebal untuk menyerap suara yang kelebihan ketika dipantulkan. Ukiran pada lis plafon supaya ruangan kelihatan lebih mewah dan megah walaupun sudah dibangun puluhan tahun dan juga ada kesan klasik pada ruangan ini” 
Karina Juwita

Desain Plafon pada Auditorium Gedung Kesenian Jakarta

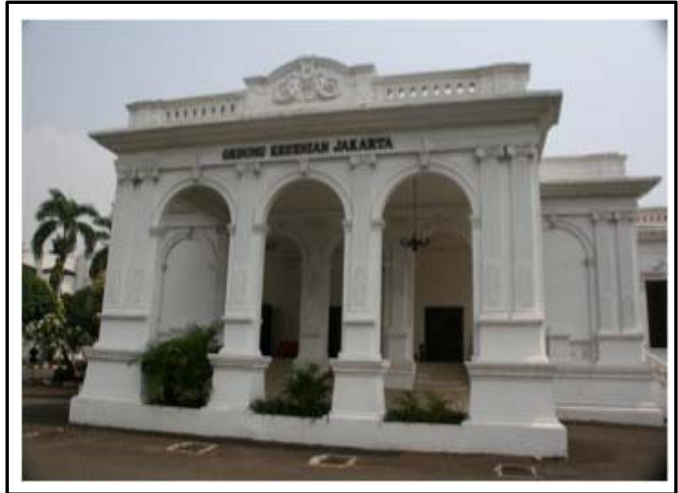

Gambar 5. Tampak Depan Gedung Kesenian Jakarta Sumber: Dokumentasi Penulis (2016)

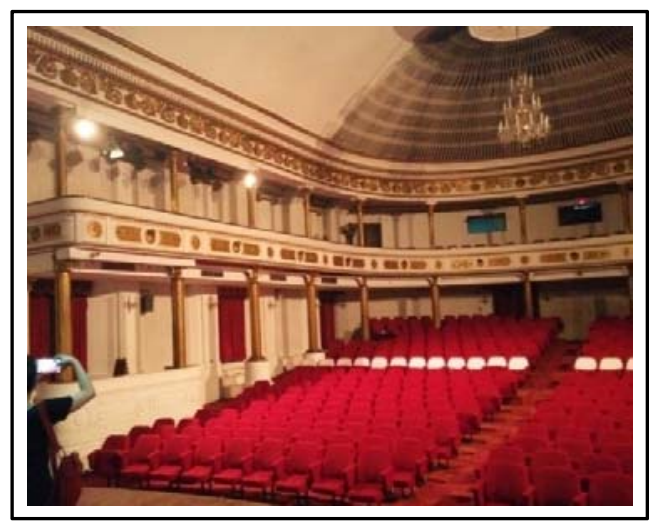

Gambar 6. Sisi sebelah kiri Auditorium Gedung Kesenian Jakarta Sumber: Dokumentasi Penulis (2016)

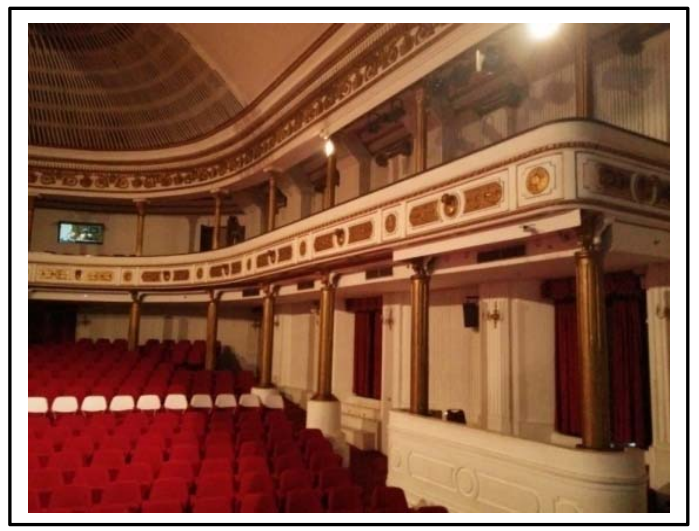

Gambar 7. Sisi sebelah kanan Auditorium Gedung Kesenian Jakarta Sumber: Dokumentasi Penulis (2016) 


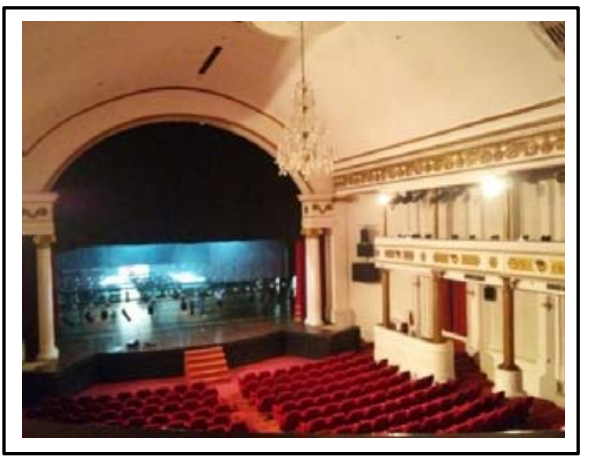

Gambar 8. Tampak Auditorium Gedung Kesenian Jakarta dari balkon Sumber: Dokumentasi Penulis (2016)

Gambar di bawah menunjukkan bentuk plafon pada Auditorium Gedung Kesenian Jakarta adalah lengkung yang berfungsi untuk memantulkan sebagian besar energi suara yang datang. Pantulan yang dihasilkan bersifat spekular (sudut datang=sudut pantul). Bentuk lengkung (busur) pada plafon gypsum akan menghasilkan pemantulan bunyi ke tempat duduk penonton. Bentuk cekung bila diolah menurut rambatan suara akan lebih mendukung kondisi akustik. Material plafon ini adalah gypsum board yang mempunyai sifat sebagai pemantul suara sehingga terjadi kurangnya penyerapan suara dan akibatnya suara sedikit terdengar dari luar auditorium. Plafon dengan bentuk busur (lengkung) juga menimbulkan kesan mewah dan megah pada ruangan.

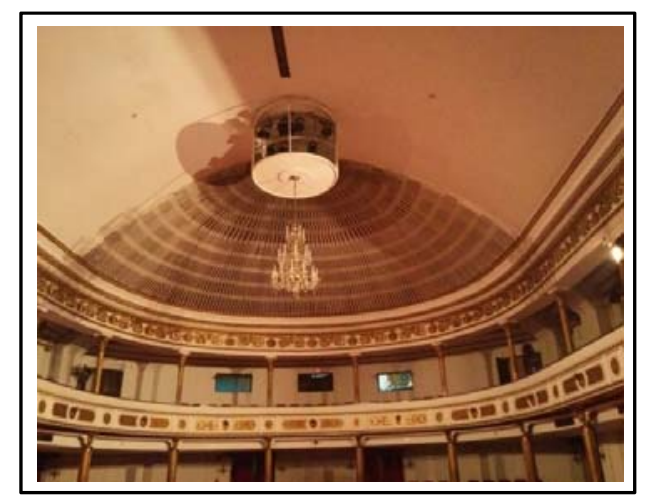

Gambar 9. Plafon Auditorium Gedung Kesenian Jakarta dari balkon Sumber: Dokumentasi Penulis (2016)

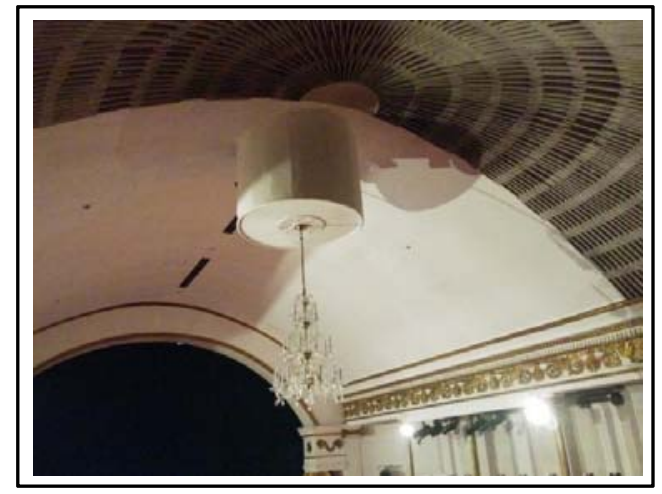

Gambar 10. Plafon Auditorium Gedung Kesenian Jakarta dari balkon Sumber: Dokumentasi Penulis (2016) 
Karina Juwita

Desain Plafon pada Auditorium Gedung Kesenian Jakarta

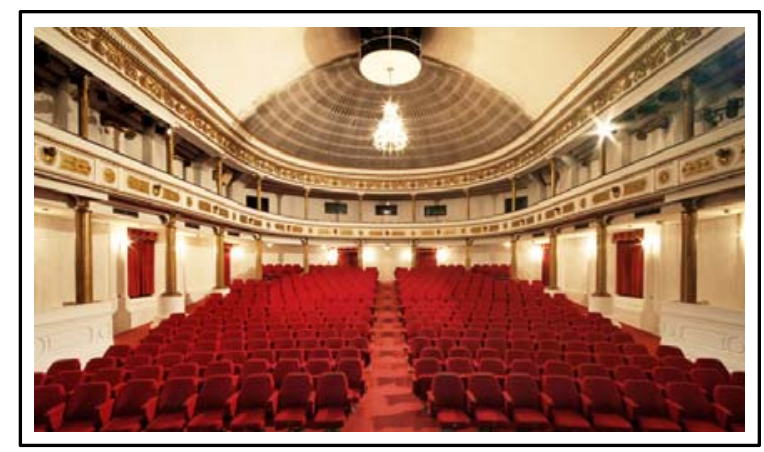

Gambar 11. Tampak Keseluruhan Auditorium Gedung Kesenian Jakarta dari balkon Sumber: Dokumentasi Penulis (2016)

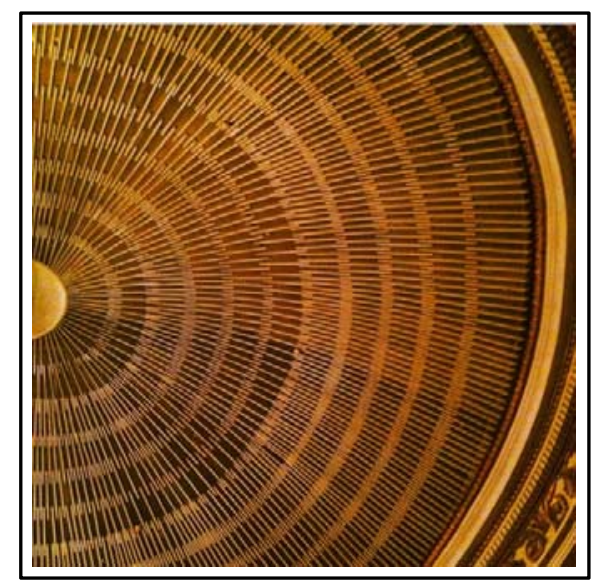

Gambar 12. Plafon Berongga pada Auditorium Gedung Kesenian Jakarta Sumber: Dokumentasi Penulis (2016)

Bentuk plafon berongga (resonator celah) yang terlihat pada gambar 13 pada Auditorium Gedung Kesenian Jakarta berfungsi untuk menyerap bunyi yang dipantulkan. Resonator celah merupakan lapisan atau layar yang berupa irisan-irisan kayu yang memiliki jarak pisah. Dengan adanya jarak pisah ini bunyi dapat lewat tanpa terhalang untuk diserap oleh bahan penyerap dibelakangnya. Jarak pisah ini disebut tembusan bunyi. Biasanya resonator celah ini digunakan untuk melindungi bahan penyerap di belakangnya. Bahan penyerap yang terdapat di belakangnya adalah panel absorber. Panel absorber ini berbahan busa tebal untuk menyerap kelebihan bunyi yang dipantulkan. Tetapi resonator celah pada plafon ruang auditorium permukaannya lebih kecil dibandingkan permukaan plafon material gypsum. Maka suara yang dipantulkan oleh plafon gypsum lebih banyak sehingga resonator celah yang berfungsi sebagai penyerap suara tidak dapat menyerap semua suara yang dipantulkan dan timbullah gema yang merambat pada ruang ketika pertunjukkan berlangsung. 


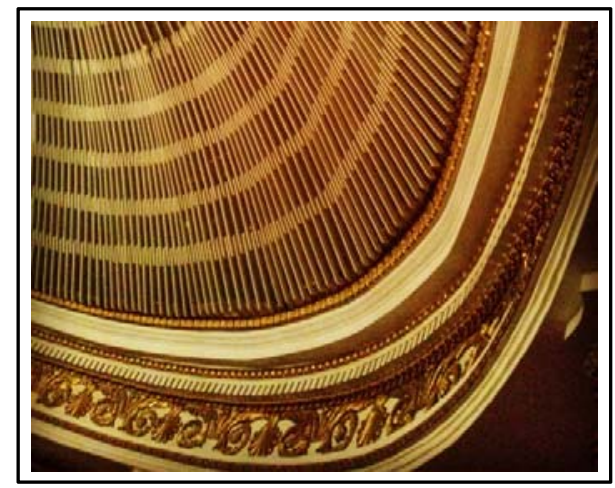

Gambar 13. Lis Plafon Auditorium Gedung Kesenian Jakarta dari balkon Sumber: Dokumentasi Penulis (2016)

Gambar di atas menunjukkan lis plafon yang bermotif dan mempunyai corak berukir mengelilingi plafon menunjukkan gaya klasik pada ruang auditorium. Lis plafon tidak berfungsi struktural, melainkan sebagai finishing atau bahan pelapis akhir yang bersifat merapikan. Dengan adanya lis, sebagai pertemuan batas antara plafon yang vertikal dengan plafon yang horizontal. Selain itu kehadiran lis plafond dapat meningkatkan nilai estetika plafond, begitu juga interiornya. Peran lis plafon tidak hanya sekadar pembatas tapi juga dengan bentuk profil lis plafon yang diperkaya dengan ornament-ornamen dapat memperindah plafon dan ruang di bawahnya.

\section{KESIMPULAN}

Berdasarkan dari pembahasan yang telah penulis paparkan pada bab sebelumnya, penulis menarik kesimpulan bahwa plafon yang digunakan pada auditorium Gedung Kesenian Jakarta terdapat cacat akustik yaitu gema yang merambat. Hal ini disebabkan karena material gypsum pada plafon sebagai pemantul suara dengan permukaan yang lebih besar dibandingkan resonator celah (penyerap suara). Resonator tersebut tidak dapat menyerap semua suara yang dipantulkan. Gema yang timbul juga terdengar hingga luar ruangan sehingga menimbulkan polusi suara ketika ruang auditorium tersebut digunakan.

Bentuk lengkung yang mendatar pada plafon juga menyebabkan kekerasan suara berkurang sehingga suara yang didengar oleh penonton paling belakang kurang jelas. Kelebihan dari bentuk plafon lengkung adalah mempercantik ruangan yang disertai dengan lis profil pada pinggir plafon. Lis plafon bukan sebagai struktural dan sebagai pertemuan batas antara plafon yang vertikal dengan plafon yang horizontal.

Saran penulis untuk plafon ruang auditorium Gedung Kesenian Jakarta sebaiknya plafon tidak dibuat mendatar, tetapi bisa dibuat secara tidak beraturan seperti naik turun permukaan plafonnya. Apabila permukaan plafon ingin tetap berbentuk cekung (lengkung) maka bisa permukaan cekung tersebut dimiringkan sehingga suara yang dipantulkan memiliki kekerasan yang cukup kuat agar dapat didengar oleh penonton secara jelas. Untuk mengatasi gema sebaiknya tidak menggunakan material bahan gypsum, tetapi menggunakan panel absorber agar suara dapat diserap secara baik dan pemantulan suara hanya terjadi di dalam ruang saja, tidak terdengar sampai keluar ruang.

\section{DAFTAR PUSTAKA}

Akmal, Imelda. (2007). Rumah Ide Plafon Kreatif. Jakarta: PT. Gramedia Pustaka Utama. 
Bradley, T. (1989). Practical Building Acoustics. Suffolk London: Sound Research Laboratories Ltd.

Doelle, Leslie. L. dan Dra. Lea Prasetyo, M.Sc. (1972). Environtment Acoustic. New York: Mc Graw-Hill Book, Company.

Doelle, Leslie. (1990). Akustik Lingkungan. Jakarta: Erlangga.

Kuttruff, Heinrich. (1979). Room Acoustics. London: Spon Press 11 New Fetter Lane.

Rettinger, M. (1970). Acoustics. New York: Chemical Publishing Company,Inc.

Suptandar, J. Pamudji. (2004). Faktor Akustik Dalam Perancangan Desain Interior. Jakarta: Djambatan.

Susanta, Gatut. (2008). Panduan Lengkap Membangun Rumah. Jakarta: PT. Gramedia Pustaka Utama.

Talaske, R.H. \& Boner, R.E. (1986). Theatres for Drama Performance. Recent Experiences In Acoustical Design. New York: The American Institute of Physics Inc. 